\title{
Cómo los vecinos se convierten en judíos. La construcción política del extraño en una era de modernidad reflexiva
}

\section{Ulrich Beck}

Universität Ludwig Maximilian

Munich

\section{Resumen}

El autor de este trabajo ofrece una serie de consideraciones acerca de la condición moderna de «extrañeidad» interpretada como desarraigo — y desde siempre la radical separación entre el ser humano y el mundo- - con su propensión a provocar las emociones más negativas, el odio y la ira, porque los extraños que han quedado sin lugar pueden «estar lejos (culturalmente) y cerca (físicamente) de cualquier parte» y a la vez «no se parecen a nosotros», por lo que con ellos se reactivan viejos marcajes como el «nosotros naturalizado-ellos extraño" y se potencia la conversión del extraño en hostis.

Palabras clave: extrañeidad, judío, vecino, modernidad reflexiva.

Abstract. How the Neighbours Become Jews: The Political Construction of Strangeness in the Age Reflexive Modernity

The author of this paper offers to us several considerations related with the modern condition of «strangeness» interpreted as uprooting with its bias generate the most negative emotions, hate and wrath, because the strangers who have fallen in a liminal nobody's land situation can «be far away (culturally speaking) and extremely close (physically speaking) of any place or anybody» and at the same time they "don't look like us» and for that reason we proceed to activate old marks such as the «naturalized we v. strange them» that could end mirroring the strange as hostis, enemy.

Key words: strangeness, jew, neighbour, reflexive modernization.

\section{Sumario}

1. ¿Qué significa la categoría «extraño» (Fremde) desde un punto de vista sociológico?

2. ¿Cómo se entiende la transición entre modernidad simple y reflexiva?
3. ¿Cómo cambia la construcción social del extraño en la modernidad reflexiva?

4. ¿Cómo las imágenes del extraño devienen imágenes del enemigo?

* Originariamente presentado en la conferencia «Modernität und Barbarei», en Hamburgo, Alemania. 
Zygmunt Bauman y Samuel Noah Eisenstadt (ambos judíos) hicieron notar el significado que tenía el emplazamiento de la conferencia «Modernidad y barbarie». Decía, en una placa situada enfrente del edificio de la conferencia:

Lugar de deportación de judíos

En 1933, en Hamburgo vivían 24.000 judíos. Desde este lugar, miles de ciudadanos judíos de Hamburgo empezaron un viaje que acabó en los campos de la muerte del régimen nazi.

La dificultad para elegir las palabras "Ciudadanos judíos de Hamburgo" señala el problema que quiero tratar: no eran los «judíos» como raza (Rassejuden) (Leyes de Nuremberg), sino los vecinos (judíos), a quienes el odio excitado públicamente y las medidas burocráticas convirtieron en extraños, en judíos de raza y sangre ajena que tenían que ser «extirpados del cuerpo político alemán» (de acuerdo con la formulación nada disimulada de las «Leyes para la protección de la sangre alemana»).

En su libro Aus Nachbarn wurden Juden (Los vecinos devinieron Judios), Hazel Rosenstrauch escribe:

Cuando se traspasó el poder a Hitler y al NSDAP, la vida de la minoría judía estaba mucho más determinada por la similitud de sus antecedentes que por la comunidad que se había desarrollado al cabo de centenares de años de persecución. Una multiplicidad de importantes diferencias filosóficas, religiosas y regionales se escondían detrás de la descripción de «judío». Había judíos religiosos y había judíos que, como mucho, iban a la sinagoga durante las fiestas importantes y que entendían de judaísmo casi tanto como sus vecinos cristianos entendían de cristianismo. Entre los creyentes había seguidores del judaísmo reformado y del judaísmo ortodoxo, cada uno con sus sinagogas, rabinos y escuelas [...], comunistas y socialistas de los hogares de ancianos judíos, la comprensión y forma de vida de los cuales ya no tenía nada que ver con el judaísmo; los cristianos bautizados que a veces se enteraban por primera vez que tenían abuelos judíos cuando tenían que demostrar su herencia aria también se volvían «judíos raciales». Ciertamente había judíos socialistas, conservadores e, incluso, un pequeño grupo de judíos alemanes nacionalistas, los cuales se identificaban con el concepto étnico de "germanidad» ${ }^{1}$.

Los soldados veteranos judíos del frente, los judíos socialistas, los judíos nacionalistas alemanes, los exóticos judíos orientales (o judíos asimilados) - todas estas diferencias, oposiciones y contradicciones «se tenían que ignorar intencionadamente», antes de que «el judío» se pudiera convertir en el símbolo de más éxito de la propaganda nazi...

La fórmula mágica incluía todo aquello que se oponía, todo aquello que no se ajustaba al sencillo y claramente descrito y definido concepto nazi del mundo. Los sindicalistas, los intelectuales críticos o los artistas que no eran

1. Hazel Rosenstraucht, Aus Nachbarn wurden Juden, Berlín, 1988, p. 11 y s. 
etiquetados racialmente como «judíos» eran considerados sirvientes de los judíos, o judíos degenerados o contaminados por los judíos bolcheviques.

La sociedad alemana creó muy artificialmente, por un periodo corto de tiempo y sólo formalmente, una «unidad nacional». El «judío estándar» es una variación del deseo de unidad nacional. El Volksgemeinschaft alemán surgió sólo en el acaloramiento del momento contra todo aquello que no era digno de confianza, contra la complejidad de una sociedad democrática con todos sus conflictos ${ }^{2}$.

Este aspecto se puede generalizar en cierto sentido: hoy hablamos, no sólo de identidad cívica, sino también de identidad cultural, de gitanos, turcos, refugiados, alemanes, franceses, suecos, rusos, etc., como si esto indicara algo de esencial y singular que es posible definir y distinguir. Hay una dificultad esencialista intrínseca (ya en el idioma alemán) en estos sustantivos y en otros que consumen y silencian la confusión y la ambivalencia. Dicho en otras palabras, hay una dificultad esencialista intrínseca en el carácter de las identidades culturales construido socialmente y políticamente.

Cómo los vecinos se convierten en judíos está bien documentado ${ }^{3}$. Cómo los vecinos acontecen judíos en el presente y en el futuro o, de manera más general, cómo los vecinos se convierten en extraños y enemigos, éste es el tema de este artículo. Quiero estructurar este tema en cuatro pasos:

1. ¿Qué significa la categoría «extraño» (Fremde) desde un punto de vista sociológico?

2. ¿Cómo se entiende la transición entre modernidad simple y reflexiva?

3. ¿Cómo cambia la construcción social del extraño en la modernidad reflexiva?

4. ¿Cómo las imágenes del extraño se convierten en imágenes del enemigo?

2. Ibídem, p. 16 y s.

3. Y así empezó: de los párrafos arios a la estrella judía. De semana en semana, desde 1933, las leyes especiales contra los judíos se intensificaron. La documentación sobre la privación sistemática de derechos que experimentaron todos los alemanes a la sazón fue recopilada por Armen von Manikowsky (disponible) en Stern núm. 6/79, 1 de febrero de 1979. Véase también la documentación de Hazel Rosenstrauch, ibídem: «No eran sólo unas "pandillas" o grupos delictivos que ya habían destruido los negocios y las organizaciones judías antes de la denominada Kristallnacht, tal y como sugieren hoy algunas lápidas conmemorativas en el lugar donde estaban las antiguas sinagogas. Con el fin de contribuir a la permanencia del milenario Reich y a "la calma de la economía", la cancillería del Reich había de intervenir regularmente cuando los asaltos en las revueltas planificadas desarrollaban su dinámica propia [...] Primero, con una definición cada vez más perfecta de aquello que era "extranjero al carácter alemán", un "enemigo del Estado" y no alemán, después, una vez la población alemana y del exterior estaban de acuerdo, los nacionalsocialistas denunciaron a aquéllos que complicaban la imagen del enemigo» (ibídem, p. 31). 


\section{1. ¿Qué significa la categoría "extraño» (Fremde) desde un punto de vista sociológico?}

Empezaremos con unos cuantos ejemplos. Extraños no son los prusianos de Prusia, sino los prusianos de Bavaria (o gente originariamente de Munich que vive en Berlín). Extraños no son los turcos de Turquía, sino los turcos de BerlínKreuzberg. Extraños son los turcos alemanes, niños turcos que nacieron, se criaron y fueron a la escuela en Alemania; quizás originariamente hablan alemán en un dialecto de Munich, pero viajan con un pasaporte turco y se sienten turistas en Turquía, su «país natal». Extraños son los afroalemanes, que son «alemanes» en su lengua, en su identidad, en su preferencia por la Navidad alemana y la comida alemana. Pero en un aspecto social muy importante no son «alemanes» - tienen la piel de color negro, y son tratados y se dirigen a ellos como el alemán medio habla y trata a los negros: «¿Tú comprender?» (Du verstehen?). Extraños son también los chinos americanos, orgullosos de su identidad étnica, si bien sin idea de la China, pero que continuamente tienen que responder en la calle cuando les preguntan dónde está el restaurante chino más próximo.

Extraños son los judíos alemanes que marchaban con entusiasmo por Alemania durante la Primera Guerra Mundial, murieron y no fue hasta hace poco que el ministro de Defensa Alemán los honró con una corona conmemorativa. Extraños son también los judíos alemanes que, con sus metales preciados de la Primera Guerra Mundial cosidos encima del pecho, fueron enviados a los campos de concentración, sin creerse que un patriota pudiera hacer aquello a otro compatriota. Extraños son aquéllos que se consideran judíos, se sienten alienados en Alemania y en Europa y obtienen su identidad (frágil) a partir de esta alienación. Un día, cuando están en China, descubren con sorpresa y horror que la categoría «judío» no tiene el menor asomo de sentido en China. Allí se les coloca dentro del saco de «europeos» y «blancos», lo mismo que sus oponentes alemanes y, por lo tanto, se ven atrapados en una difícil crisis de identidad.

Por otro lado, una afroalemana escribe: «Siempre me ha gustado ser "mulata”, incluso durante los tiempos terribles del nacionalsocialismo. He podido llevar muy bien aquello que tengo de blanca y aquello que tengo de negra. Recuerdo cuando un colega me preguntó durante los terribles años cuarenta si me sentía muy desgraciada por tener que vivir como "mulata". Le dije: "No, porque aquello que he experimentado hasta ahora debido a mi origen étnico, tú no lo experimentarás nunca en toda tu vida» ${ }^{4}$.

No es infeliz, si bien ser un extraño y estar en un país extranjero comporta el estereotipo de la desgracia. Judío cuando se quiere ser alemán. Judío y alemán, es decir «blanco», cuando se está en la China. Considerado chino

4. «Unser Vater War Kameruner, unsere Mutter Ostpreussin, wir sind Mulattinnen. Die Schwestern Frieda P. und Anna G. Erzählen aus ihrem Leben», en: Koguntoye et al., Farbe bekennen, Frankfurt am Main, 1992, p. 84. 
cuando se considera un verdadero norteamericano. El prusiano asimilado en Munich, el franco que de repente descubre que es no bávaro, que los bávaros de Munich son unos explotadores y que, de hecho, ya lo han explotado. ¿Cuál es el común denominador aquí? ¿Hay una o más características conceptuales que puedan identificar esta colección de inverosimilitudes y la gente con identidades múltiples como defectos e incidentes de "extraños»?

De hecho, jéste es exactamente el caso! Todo el mundo que quiera conocer a fondo la categoría del extraño tiene que ir acostumbrándose a la contradicción ${ }^{5}$. De manera general, podemos decir que la categoría del extraño surge de entre las categorías y los estereotipos establecidos del mundo local (el mundo de la gente del lugar). Los extraños no encajan dentro del pulcro envase donde deberían encajar, y de aquí viene la extrema irritación. Dicho de otro modo, los extraños son los excluidos realmente de los estereotipos del orden social. Son judíos cuando deberían ser alemanes, y alemanes cuando deberían ser judíos. Son afortunados cuando deberían ser desdichados (y viceversa). Son nativos, generaciones futuras, gente del lugar — pese a que la gente del lugar los excluya porque son «extraños».

Sobre cómo son «de extraños» los vecinos en su autoimagen hacia la gente del lugar - aunque esta gente del lugar les quiera mal y ellos mismos tengan que luchar en contra como enemigos - escribe vívidamente Jean Améry en su libro Jenseits von Schuld und Sühne. Escribe en torno a un incidente como miembro de la resistencia del nacionalsocialismo:

Un día, el alemán que vivía en nuestro escondrijo se molestó por las conversaciones y el alboroto que hacíamos durante su siesta. Subió, golpeó la puerta y entró pisando fuerte: iquien lo hubiera dicho nunca! un hombre de la SS con las solapas negras y los símbolos de la policía de la seguridad bordados. Nos quedamos blancos de miedo, porque las herramientas de nuestro trabajo de propaganda contra la permanencia del Reich estaban en la habitación contigua. El hombre dio una orden, pero lo que entonces me pareció más terrible fue que lo hizo en el dialecto de mi pueblo natal. Hacía mucho tiempo que no había oído aquella entonación, y por aquella razón sentí el loco deseo de responder en su propio dialecto. Me vi en una situación emocional paradójica, casi perversa, de miedo tembloroso y, al mismo tiempo, de calidez familiar» ${ }^{6}$.

Este ejemplo refuta aquello que a menudo se considera esencial, como un estereotipo conceptual de la categoría de extraño, incluso en las ciencias, es decir, la oposición a la gente del lugar. Una y otra vez se ha afirmado que existe una formación de identidad mutua, tanto de la acción social como de la política en términos encontrados, «nosotros-ellos», "del lugar-extraños». Al mismo tiempo, la categoría del extraño se confunde con la categoría del extran-

5. El artículo definido — «el extraño o los extraños»— es del todo inapropiado, convierte la indefinición categórica del concepto en todo lo contrario.

6. Jean AMERY, Jenseits von Schuld und Sühne, Stuttgart, 1977, p. 85. 
jero. Los extranjeros — francés, inglés, indio, sudafricano- incluso cuando están entre nosotros, saben adonde pertenecen. Obedecen las normas nacionales del orden mundial. Los estraños son, por otra parte, franceses o africanos, desde nuestra perspectiva. Son vecinos. Por encima de todo, están cerca. «No tengo nada en contra de los extraños. Mis mejores amigos son extraños. Pero este extraño es de aquí", dice Astérix. La categoría del extraño quiere decir: el distanciamiento de la proximidad a través de la intimidad, lo cual no tiene que llevar en ningún caso a la comprensión mutua.

Los extraños entienden "la unidad de proximidad y lejanía», escribe Georg Simmel, de la siguiente manera: «distancia significa que aquél que está cerca está lejos, y rareza significa que aquél que está lejos está cerca [paráfrasis del autor]. Los habitantes de Sirius no son realmente extraños para nosotros, al contrario, para nosotros no existen, están más allá del lejos y del cerca. El extraño es un elemento del grupo mismo, como los pobres [...]» ${ }^{7}$. Esta proximidad del extraño presupone (relativamente) formas de vida «local» tranquilas y ordenadas; sólo entonces es el extraño «el vagabundo que llega hoy y se queda mañana $[. ..]{ }^{8}$. Expresado de otro modo, en un mundo móvil o bien ya no hay extraños o bien todos lo son.

Los extraños son, pues, vecinos; es decir, ¡no son como «nosotros»! Con respecto a su categoría, los extraños son una doble provocación: son del lugar, pero no obedecen a los estereotipos que los mismos del lugar crean y mantienen.

Hazel Rosenstrauch relata cuan fácilmente se pueden equivocar los del lugar cuando describen las características de su localidad:

Al principio del Tercer Reich, cuando a los niños judíos aún les estaba permitido visitar las escuelas públicas alemanas, había multitud de historias sobre cómo durante una clase se presentaba a un niño como objeto de demostración, y se explicaban las características de la raza nórdica a partir de su fisionomía, y los niños no se podían aguantar la risa, porque el hombre de la SA había llamado a un niño judío [...] Debe haber sido difícil creer en la superioridad y la belleza de la raza aria en presencia de Goebbels, Göring e incluso Hitler?.

Ni la proximidad ni la peculiaridad de quien es singular son naturales, al contrario, tienen que ser construidas socialmente delante de contradicciones. Una mujer habla alemán en un dialecto de Munich y tiene la piel negra. Aquí radica un motivo más de irritación: cuando una mujer negra de Munich no tan sólo es posible, sino también real y viva, el mero ser, la sola existencia, refuta la naturalidad de las fronteras y los estereotipos a partir de los cuales la gente del

7. Georg SIMMEL, «Exkurs über den Fremden», en: Soziologie. Untersuchungen über die Forman der Vergesellschaftung, Berlín, 1968, p. 509. "The Stranger», en: The Sociology of Georg Simmel, trans. Kurt H. Wolff, Nueva York, 1950, p. 402-403.

8. Ibídem, traducción inglesa: p. 402.

9. Hazel Rosenstrauch, Aus Nachbarn, p. 32. 
lugar ha construido su mundo y su orden social. Los extraños son, pues, una refutación viva de los límites y de los fundamentos naturales aparentemente claros, por los cuales la pertenencia y las identidades se expresan en el Estado nacional.

Estrechamente conectada con esta segunda característica de que los extraños son la personificación de la exclusión y se encuentran entre categorías, se presenta una tercera categoría: la relatividad de la rareza de los extraños. Que, desde la perspectiva propia o la de los otros, algo o alguien se perciba como «extraño» depende, de manera banal o no tan banal, del marco de referencia que se da por descontado. Sólo se tiene que pasar por alguna frontera para ponerse en el lugar del extraño. Sin embargo, permitidme clarificar los puntos fundamentales con una historia. En las postrimerías de los años treinta, dos emigrantes judíos hablaban de sus planes. Uno quería emigrar a Uruguay. « ¿Tan lejos?», se maravilló uno. "¿Lejos de dónde?», replicó el otro.

Esta pregunta, «¿lejos de dónde?», identifica esta visión con la visión del extraño. Ha perdido el sentido del lugar del que podría estar más cerca o más lejos. Este extraño ha perdido el punto de referencia de estar aquí, de estar en casa. Hay nativos y extranjeros, amigos y enemigos - y hay extraños que no encajan categóricamente en este modelo, que rehúyen, obstruyen e irritan aquellas oposiciones. La relatividad del extraño existe, como se ve claramente aquí, porque el extraño es un concepto sin un contraconcepto.

Una afroalemana relata su intento de descubrir su identidad en África:

Mientras paseaba por la playa, vi a unos niños que buscaban algo útil en un montón de basura. Me gritaron "iBlanquita, blanquita!» y otra vez me sentí etiquetada y marcada. Había creído que podía apropiarme de una identidad negra africana, pero esta vez me habían gritado como si fuera blanca. Estaba pasmada y no pude hablar con nadie. No sería hasta mucho más tarde que encontraría una explicación a este incidente. Mi comportamiento, la distancia observadora, me había traicionado; en cada escena yo estaba o demasiado distanciada o demasiado interesada en pasar por una nativa. Mi conducta me señalaba como europea. Porque, en los clichés, los europeos son blancos, y así en aquel momento me convertí en una persona blanca. En este caso, el blanco era una categoría social, nada diferente de lo que pasa con la clasificación de «negra» ${ }^{10}$ - la raza como construcción social.

El negro alemán es calumniado como blanco por negros africanos. Esta inversión muestra exactamente qué significa la relatividad del extraño, pero también hace evidente lo poco que el extraño y la rareza se pueden conceptualizar e identificar naturalmente o biológicamente.

¿Cómo se entiende teóricamente este resultado? Reinhard Koselleck sugiere que, en el campo de la acción política y la historia política, diferenciamos

10. E. Wiedenroth, "Was macht mich anders in den Augend der Anderen?», ed. K. Oguntoye et al., Farbe bekennen, 169 y s. 
entre antónimos simétricos y asimétricos. Entre los primeros, incluye comparaciones generales como amigo y enemigo; entre los últimos, incluye términos opuestos asimétricos tales como bárbaro-griego, pagano-cristiano, subhumano-superhombre. Así, estos contraconceptos indican que su oposición es contraria de manera desigual. Aquí nos tenemos que preguntar cómo este punto de vista encontrado - bárbaro, pagano, subhumano - se pasa por alto.

Considero que es importante reconocer que la categoría del extraño rehúye exactamente estos contraconceptos. Koselleck diferencia varias ordenaciones sociales - una simétrica, la otra asimétrica y jerárquica. La categoría del extraño, por contraste, invalida cada tipo de ordenación conceptual.

Los extraños no son, al menos desde la perspectiva que he descrito aquí, el contraconcepto del concepto «gente del lugar». Los extraños son gente del lugar (vecinos); y son a la vez, en ciertos aspectos (a veces desde su perspectiva, a veces sólo desde la perspectiva externa de la gente del lugar) no del lugar. Dicho de manera general: la categoría de extraño es el contraconcepto (o transconcepto) de todos los conceptos del orden social. Y aquí radica su irritación y provocación - ya como concepto ${ }^{11}$.

La entrada a este punto de vista es que los extraños no siempre son sólo extranjeros, la nacionalidad de los cuales se mantiene por estereotipos del orden del Estado nacional. Los enemigos mismos son, por decirlo de manera incisiva, menos amenazadores que los extraños, porque obedecen al orden establecido de estereotipos del yo y de los otros. "Por su mera presencia», escribe Zygmunt Bauman, «que no encaja fácilmente en ninguna de las categorías establecidas, los extraños niegan la validez misma de las oposiciones aceptadas. Desmienten el carácter "natural" de las oposiciones, exponen la arbitrariedad, ponen a cuerpo descubierto la fragilidad» ${ }^{12}$. Dicho de otro modo, los extraños son un buen ejemplo de la evidencia de que la «naturalidad» de orden local es artificial y convencional. Por las contradicciones que encarnan (mesuradas por imágenes predominantes del yo en el mundo social), los extraños demuestran una y otra vez algo nuevo, que el mundo también podría ser diferente ${ }^{13}$.

Que los extraños son del lugar y no solamente extraños, como piensa la gente del lugar, lo comenta Michael Landmann: «La práctica religiosa judía no existía en mi familia ni siquiera en las reliquias [...] aquello que tres generaciones nos habían dado nos determinó de manera más fuerte que nuestro origen remoto por bien que conocido. Éramos judíos de manera más pronunciada a los ojos del mundo que a nuestros propios ojos». Y continúa: «Tras el exterminio de seis millones de judíos por parte de Hitler, yo sólo era una cosa: judío [...] La claridad entraba con mucha dificultad, la confianza en la vida y en la humanidad no volvió a ser completamente [...] nos queda, no obs-

11. Esta irritación también la expresa en latín la palabra hostis, que significa 'enemigo' y 'huésped'.

12. Zygmunt Bauman, Thinking Sociologically, Cambridge, Blackwell, p. 55.

13. Esto también es válido en el ejemplo de los homosexuales, y aún más directamente para los bisexuales. 
tante, una cosa: ninguna ley puede negar el profundo y doloroso amor por la cultura alemana» ${ }^{14}$. Repito esta frase, "ninguna ley puede negar el profundo y doloroso amor por la cultura alemana». Dicho en pocas palabras, los extraños són la ambivalencia como existencia ${ }^{15}$.

Con el fin de aclarar y explicar la categoría de «el extraño», tenemos que evitar, como mínimo, equiparar y poner al mismo nivel los extraños con los extranjeros y los solicitantes de asilo, deteniendo, de este modo, la degradación inclusiva. Los extraños podrían ser el enriquecimiento que una y otra vez revienta las fronteras del yo y su estrechez de miras. Despiertan nuevos mundos y perspectivas curiosas y abiertas. Esto es así incluso en la siguiente generalización profana: el restaurante tailandés de la esquina y la industria turística son una «industria de extraños». Ellos comercializan rareza, viven del deseo colectivo de refrescarse durante «los mejores años de sus vidas» (como se suele decir) en un país extranjero como si estuvieran en la fuente de la juventud.

Los alemanes son ambas cosas: están especialmente dispuestos a dar y a gastar dinero fácilmente para gente de otras culturas y países que necesitan ayuda - por ejemplo: la ayuda alemana en Rusia en el invierno de 1992, cuando trenes enteros llenos de donativos con la solidaridad oficial fueron hacia el este, mientras los alemanes tiraban cócteles molotov a víctimas inocentes etiquetadas como «extraños». A veces, los dos coinciden en una misma persona. Aquél que ya ha hecho una batida dentro de su armario de la ropa para enviar ayuda para el invierno ruso, se moviliza en contra de una residencia para los solicitantes de asilo en su barrio. ¿Cómo encaja esto? Aquí se cruzan dos tipos sociales de relaciones: «el extranjero», distante y necesitado, y «el extraño», con demandas oficiales de ayuda social en nuestro propio vecindario. La disposición a la ayuda aumenta con la distancia en kilómetros. Los celos y el odio hacia los extraños aumenta proporcionalmente a medida que los extraños pierden rareza y, contrastando con los numerosos turistas, se ven como competidores por los escasos derechos estatales.

En resumen, la peculiaridad del concepto «extraño» surge porque es un concepto sin un contraconcepto. Los extraños están, por lo tanto, determinados no tan sólo por el hecho de estar delimitados por los otros; están determinados mucho más por el hecho que minan y revientan por dentro todas las categorías polares del orden social. Los extraños no son ni enemigos ni amigos; ni nativos ni extranjeros; son cerca y no cerca, lejos, pero aquí; son vecinos aislados por los vecinos, como no-vecinos, como extraños. La rareza de los extraños se muestra sobrecogedora y tentadora.

14. Michael Landmann, «Mein Judentum», en: Mein Judentum, ed. H.J. Schultz, Munich, 1978 , p. 116,120 y s.

15. Esta ambivalencia es generalizable; también determina, por ejemplo, el debate entre feministas y postfeministas. ¿Qué quiere decir feminidad? Con la creciente igualdad entre hombres y mujeres, la claridad de "ser una mujer» ha sido olvidada. Quizás «la ambivalencia como existencia» dará paso a una característica biográfica de la «modernidad reflexiva» (insistiremos sobre esto más adelante). 
Los extraños equidistan del conocimiento y de la ignorancia porque los extraños son sencillamente allá, presentes en su propio horizonte de conocimiento y percepción. Pero, al mismo tiempo, la rareza de los extraños presupone una rotunda ignorancia. El comportamiento de los extraños se remonta estereotípicamente a las características desindividualizadas del colectivo - de los turcos, de los gitanos, de los judíos, de las mujeres, etc.- , pero no a los motivos, a las razones, a las circunstancias y a la historia individual de la persona. El comportamiento propio y el del yo son, por contraste con el estereotipo, individualmente entendidos y explicados. Cada hombre o mujer actúa aquí como persona y no como representante del colectivo.

La lista de oposiciones se amplía, el principio fundamental permanece: la particularidad de la categoría de «el extraño» no se expresa dentro de las oposiciones del orden social, más bien radica en la oposición a todas las oposiciones, la cual, a su vez, no reconoce ninguna oposición. La categoría de «el extraño» significa, en otras palabras, sentarse a mitad de camino entre dos asientos: la ambivalencia como existencia.

Sin embargo, esta definición ambivalente del extraño presupone aún un mundo relativamente sencillo. En primer lugar, hay el "nosotros», que excluye más o menos claramente el «ellos». En segundo lugar, la gente «del lugar» tiene la mayoría absoluta. Los extraños son una minoría «fugitiva». Esta condición la quiero denominar la "constelación de la modernidad simple». La construcción social del extraño tiene lugar aquí, en un contexto de relativa claridad: la gente del lugar tiene su espacio dentro de la estructura del orden social contra la cual los extraños son refrenados y de donde son excluidos.

\section{2. ¿Cómo se entiende la transición entre modernidad simple y reflexiva?}

Es precisamente esta estructura de fronteras imaginadas, mayormente por el Estado nacional, y de sentido de pertenencia minado al interior y al exterior, la que se ve alterada con el proceso de «modernización reflexiva». En el interior, la identidad del individuo autorregional y nacional, mediante varios procesos de movilización, se ve borrosa, incierta y removida; en el exterior, crecen las redes entre y sobre las naciones — de las redes económicas, de información y de telecomunicaciones, a la destrucción medioambiental y el transporte sin fronteras de contaminantes del aire, del agua y de los alimentos. Esta fase en la que la modernización altera las condiciones generales y el orden categórico de la modernización societal industrial es lo que yo describo como «modernización reflexiva». Esto se puede resumir de manera teórica en tres principios:

Primero, incertidumbre fabricada; este teorema no implica necesariamente que nuestra existencia se haya vuelto más precaria en el ámbito individual o colectivo. La aparición y el alcance de los riesgos ciertamente han cambiado. Las consecuencias del desarrollo técnico e industrial ponen en entredicho las normas — la racionalidad — de su anterior gestión, por ejemplo: la asegurabili- 
dad privada. La incertidumbre fabricada no es tan sólo el resultado de la intervención humana en las condiciones sociales y naturales de la existencia; esta interferencia viola el «contrato de seguridad» que ha sustentado el consenso del progreso de la sociedad industrial ${ }^{16}$.

Segundo, estas situaciones de peligro para la civilización ya no se pueden entender ni vencer en la esfera local o nacional. Entendemos por globalización no un fenómeno meramente económico; sería falso equiparar la globalización a la aparición de un sistema mundial o de una sociedad mundial. Entiendo el término "globalización» (en línea con Anthony Giddens) como acción a través del espacio - un proceso que surge por la transformación del espacio y del tiempo, como resultado de las posibilidades globales de los medios de comunicación y del transporte de masas ${ }^{17}$. De este modo, no sólo se crean redes mundiales, sino que los horizontes de experiencia locales y personales se rompen y se alteran por dentro. Nuestras actividades cotidianas se ven cada vez más influenciadas por sucesos que pasan al otro lado de la Tierra. Por contraste, los estilos de vida locales tienen efectos mundiales y encuentran una propagación mundial. La globalización, en este sentido, es un proceso complejo que genera conflictos y nuevas fronteras. Así, la aparición del nacionalismo local y la articulación de identidades étnicas locales pueden ser entendidas como una consecuencia de la globalización, lo cual parece contradecirla. Esta correlación se puede observar actualmente en Rusia.

Tercero, destradicionalización e individualización. Con esto me refiero al agotamiento, la disolución y el desencanto de los orígenes específicos de identidad y significado del colectivo y del grupo (identidad étnica, conciencia de clase, creencia en el progreso) de la sociedad industrial, la cual, hasta los años sesenta, había salvaguardado las democracias occidentales y la sociedad económica. La consecuencia es que todos los intentos por definir se impondrán al individuo mismo. Éste es un aspecto esencial de «la individualización societal».

¿Qué diferencia este «teorema de la individualización» de los significados paralelos que Georg Simmel, Émile Durkheim y Max Weber presentaron a

16. Aquello que aquí denomino «incertidumbre fabricada» lo he denominado públicamente "grandes peligros» en el Gegengiften (Frankfurtt/M., 1988; traducción inglesa: Ecological Politics in an Age of Risk, Cambridge, 1995, y lo diferencio de «riesgos». La expresión «incertidumbre fabricada» es ciertamente más amplia, no tan sólo tiene que ver con desarrollos técnicos, sino también con conmociones económicas, erosiones del Estado social, del sistema político y con el Estado de seguridad constitucional y burgués. Véanse, entre otros, F. EWALD, Der Vorsorgestaat, Frankfurt/M., 1993; W. BONSS, «Unsicherheit als soziologisches Problem», en Mittelweg, núm. 36 (febrero/marzo de 1993); también Anthony GidDENS Beyond Left and Right, Cambridge, 1994; Ulrich BECK, Anthony GIDDENS y Scott LaSH, Reflexive Modernization, Cambridge, 1994.

17. Anthony GIDDENS, The Consequences of Modernity, Stanford, 1990. 
principios de este siglo? Hoy, la gente no sale de la seguridad del estatus y la cosmología religiosa para entrar en el mundo de la sociedad industrial, más bien sale de la sociedad industrial del Estado nacional a la turbulencia de la sociedad del riesgo global. La gente se enfrenta a una vida con riesgos globales $\mathrm{y}$ personales que son diferentes y contradictorios ${ }^{18}$.

La individualización no implica sólo la disolución, sino también la capacitación para hacer el descubrimiento de las tradiciones. El idílico pastel de manzana de la abuela, los «nomeolvides» y el comunitarismo están en su punto álgido.

En este sentido, la incertidumbre fabricada, la globalización y la individualización se desarrollan como momentos parciales de una teoría de «modernización reflexiva ${ }^{19}$. Esto no significa una reflexión sobre la modernización, sino «reflexividad», en el sentido de un no intencionado, y a menudo inadvertido, cuestionamiento del yo, de un cambio personal y de la superación del yo. La modernización mina y cambia las premisas y las condiciones generales de la modernización social industrial claramente de acuerdo con la incertidumbre fabricada, la globalización y la individualización. Tienen una cosa en común: surgen de la continuidad de la simple modernización y existen en la tradición de la sociología clásica, sin embargo, minan las controversias sociológicas sobre los fundamentos del capitalismo industrial del Estado nacional y los fundamentos de la sociología tradicional. Que la sociología podría convertirse en el anticuario de la sociedad industrial está, paradójicamente, bien fundamentado en la modernización de la modernidad, aún privada de los conceptos y las teorías de la sociología.

Bajo las condiciones de la modernización reflexiva, la construcción social del extraño ya no se puede limitar a la autocomprensión cultural de un círculo social cercado, y la definición del yo, por lo tanto, deviene particularmente problemática. Individualización significa que la cultura del yo se fragmenta, se diferencia. Una persona puede nacer en Osfriesland, ir a la escuela en Münster y en Hameln, trabajar en Bamberg y casarse en Fribourg; su pareja puede ejercer su profesión en Leipzig, pueden pasar las vacaciones en Tenerife, o en una isla griega, y tener frecuentes contactos profesionales con Escandinavia o con países y lenguas de la Europa del Este.

Sighart Neckel formula esta consecuencia, «lo que Georg Simmel consideraba un indicio del extraño - "el vagabundo que llega hoy y se queda mañana"ya se ha convertido en una forma general de vida en esta era del individuo» ${ }^{20}$.

Dicho de otro modo, la modernidad reflexiva generaliza la categoría del extraño en una categoría que tiene como característica central la universalización de lo extraño. Más y más gente pierde su definición social a través del origen y el lugar social. Las identidades están mezcladas; las fronteras ya no resisten ni

18. U. Beck y E. Beck-Gernsheim, The Normal Chaos of Love, Cambridge, 1995; U. BeCK y E. BeCK-Gernsheim (eds.), Risjkante Freiheiten, Frankfurt am Main, 1994.

19. U. BECK, «Die Erfindung des Politischen», en: Reflexive Modernization.

20. S. NECKEL, "Gefährlich Fremdheit», Ästhetik und Kommunikation, núm. 85/86, mayo de 1994 , p. 47 y s. 
limitan. La gente convive con extraños para quienes ellos mismos también son raros. «La sociedad moderna sólo puede generalizar la rareza porque ella misma vence, al mismo tiempo, la rareza como un estatus especial por el cual todo el mundo es un extraño. Para formularlo paradójicamente, sólo cuando ya no queden extraños podrá todo el mundo ser extraño» ${ }^{21}$. La pregunta ya no es, ¿̨cómo tratamos «nosotros» a los «extraños»?, la pregunta es, ¿cómo se tratan entre ellos los extraños de una y otra clase? ¿Cómo se mueve y cambia la categoría y la situación de los extraños bajo las condiciones de su generalización?

Erving Goffman ha examinado los resultados de la generalización de la rareza. Habla del hecho que las consecuencias de la modernidad en las relaciones cotidianas de la gente, desconfianza y miedo y una clase de «desatención civil» —indiferencia civil, desconsideración civil- sustituyen el «nosotros» y el «ellos». Una actitud tan activa, que se presenta con cuidado, tiene que ser equilibrada y constante.

En la multinacional y multilingüe Suiza (quizás un país modelo de rareza generalizada, una pequeña Europa de bolsillo en formato suizo) se habla de «ignorancia tolerante» o de "tolerancia ignorante». Ciertamente, una razón esencial para la diferencia moral radica aquí en la mucha gente que permite los ataques públicos y los actos violentos que tienen lugar contra los «extraños». Tratamos con un patrón de conducta altamente frágil y delicado, que depende del reconocimiento mutuo, y que en las metrópolis-jungla, cada vez más violentas, tan sólo se puede mantener parcialmente.

\section{3. ¿Cómo cambia la construcción social del extraño en la modernidad reflexiva?}

¿Quiere decir esto que en la modernidad reflexiva la relación con los «extraños» no será problemática? No, bien al contrario, como lo demuestran con detalle los resultados de la modernización reflexiva. Individualización significa también que la identidad del yo se hace borrosa. Globalización significa especialmente que las paredes de la distancia se vienen abajo; el extraño y lo extraño se ven cada vez más atrapados en los horizontes de sus propias vidas. La incertidumbre fabricada implica que el peligro está siempre al acecho, y nadie hace nada. Una posible consecuencia es que mucha gente ve amenazado su propio mundo global por parte de una extrañeza universal. Todos los niveles y ángulos de la sociedad se movilizan contra esto. Se reduce a una cuestión que impresiona a toda la sociedad -la politización de la cuestión de la seguridad ${ }^{22}$. Cuando

21. A. HaHN, «Die sociale Konstruktion des Fremden», en: W. M. Sprondel (ed.), Die Objektivität der Ordnungen und ihre kommunikative Konstruktion, Frankfurt/M., 1994, p. 162.

22. El término inclusivo incertidumbre se confunde con aquello que en inglés está separado, y con razón, en dos palabras: insecurity y unsafety ('inseguridad' y 'peligrosidad'). Inseguridad por la desaparición de los estilos de vida tradicionales o por la amenaza debida a la violencia desinhibida o a la criminalidad; sin olvidar la dramaturgia de la caída de las monedas ni el crimen (organizado), que impulsan el neonacionalismo en Europa. 
sea en terreno inseguro, un extraño hará bien, aconseja Ronald Hitzer, de encarar aquello que le amenaza «con —en lugar de sin — prejuicios».

Aislarse, cerrarse, esconderse —éstas son hoy las maneras más usuales de reaccionar a la ansiedad ante las cosas que pasan "allí fuera», de reaccionar frente a las cosas que parecen amenazarnos bajo diferentes máscaras. Cerrojo en la puerta, cerraduras en la entrada, múltiples sistemas de seguridad, alarmas y cámaras de vigilancia que se extienden desde las mansiones de clase alta hasta las zonas de clase mediana. Vivir detrás de una pared de cerraduras metálicas y de paredes electrónicas, alarmas, esprais paralizantes, pistolas de gas lacrimógeno y de electrochoque, es parte de la orientación urbana de supervivencia del individuo.

Emerge una multicultura «del egoísmo, el etnocentrismo, la estrechez de miras, la desconfianza, los celos, la queja, las exigencias, las objeciones; una multicultura de límites activos y de intolerancia ignorante» ${ }^{23}$. Sin embargo, el contexto, los actores, las autoridades y los recursos de la construcción social del extraño cambian.

Agnes Heller, de los Estados Unidos, explica:

Ya hace tiempo que "una retórica de la raza» ha sustituido a la retórica de la "cuestión social», lo cual quiere decir que, por cuestiones de raza, también se han institucionalizado unas claras reglas de juego. Estas reglas institucionales del lenguaje por cuestiones de raza y género están incluso conectadas en la esfera privada. Ni dentro de su propio apartamento, con amigos, uno puede usar palabras prohibidas o explicar chistes (sobre negros, judíos, homosexuales), porque se podrían tergiversar. Y cualquiera que sea denunciado puede llegar a perder el trabajo [...] Tan sólo la autorrepresentación de un grupo se considera aún la única forma legítima de representación de este grupo. Toda representación por otro (por ejemplo, la representación de negros por blancos, de mujeres por hombres, de homosexuales por heterosexuales) es considerada, por definición, «racista» $\mathrm{y}$ «sexista». El único contacto legítimo entre razas (y géneros) es la lucha; la alternativa es el autoaislamiento mutuo y su normalización. Los racistas modernos repiten los viejos argumentos racistas: el otro no siente lo mismo que nosotros, tiene otra historia de conocimiento, no puede ni entender aquello que pensamos, cómo padecemos (aguantándolo) y así sucesivamente. MacKinnon, para quien el censor es la llave de la rectitud, «sabe» (¿cómo?, me pregunto) que los hombres (claro está, sólo hombres) consumen productos pornográficos, y piensan en la pornografía mientras ella da clase. ¡Llamad a la policía del pensamiento! ${ }^{24}$.

La nueva fronterización del mundo, la separación y fortificación de «nosotros» $\mathrm{y}$ "ellos» está siendo gestionada con los medios y la autoridad de la sociedad civil, por decirlo de alguna manera, como una iniciativa civil mundial de una subcorriente política.

23. R. HitZler, «Mobilisierte Bürger», Ästhetik und Kommunikation, p. 58-59.

24. A. Heller, «Die Zerstörung der Privatsphäre durch die Zivilgesellschaft», ibídem, p. 25. 
Se trata de disciplina y castigo. Y se trata de control. Si las irregularidades comportan la pérdida de un puesto de trabajo, medios de comunicación, sala de exhibición, etc.; se controla la sexualidad, los hábitos del habla, el comportamiento y las formas de representación — hasta el más pequeño detalle. Ya desde el comienzo, cuando aún no se había dicho casi nada al respecto, Foucault observaba que el discurso más devastador de poder de nuestro tiempo no lo creó el Estado moderno, al contrario, lo produjo y lo dirigió el poder y la autoridad de la sociedad «civil». La sociedad civil ha resultado ser del todo incivil $^{25}$.

En Europa, donde la sociedad nunca dominó al Estado, sino que el Estado dominaba a la sociedad, asistimos a un cambio de escenario y de estrategia - por decirlo claramente- de los extraños construidos culturalmente a los construidos burocráticamente. El extraño «burocrático» no es, al contrario que el extraño "cultural», vago y categóricamente incomprensivo. A guisa de ejemplo, viene a la mente el nuevo término despectivo alemán Asylant ${ }^{26}$. Este término no equivale a su honónimo en inglés; en el idioma de las Naciones Unidas, el término relacionado con los «refugiados» tiene el origen en el alemán administrativo, legal y oficial. Un Asylbewerber ('solicitante de asilo político') es diferente del Asylberechtigten ('persona con derecho de asilo político'). Tiene que ver con un grupo oficialmente definido de extraños recluidos en barracas. Es interesante notar que el término Flüchtling ('refugiado') está reservado para alemanes en el idioma jurídico y político de la República Federal. Un Flüchtling ('refugiado') es, por definición, alemán. Diana Wong escribe:

Debido a la carencia de una posibilidad de definición jurídica y sociológica precisa, el término Asylant corre desbocado — por decirlo así- por el discurso social. A quién hace referencia este término continúa siendo poco claro y contradictorio. Hay varias respuestas: el solicitante reconocido de asilo, o el solicitante no reconocido de asilo, o sólo el solicitante de asilo, o un término colectivo para todos los refugiados extranjeros. Sigue siendo contradictorio y poco claro qué quiere decir este término: los auténticos perseguidos políticos, los refugiados que huyen de la pobreza, los refugiados económicos, los criminales extranjeros, los traficantes negros de drogas. Su poder semántico aumenta a causa de los numerosos y sugestivos eslóganes que, examinados minuciosamente, no obstante, están vacíos de contenido. El término «solicitante de asilo» sirve como término fundamental para combinaciones como: «alud de solicitantes de asilo», "marea de solicitantes de asilo», "catástrofe de solicitantes de asilo», «turismo de solicitantes de asilo», y «pseudosolicitantes de asilo». El acortamiento de la palabra, Asylanten a Assi, está íntimamente ligado a algo que en el uso popular tiene un significado asocial ${ }^{27}$.

25. Ibídem, p. 26.

26. Asylant es un término peyorativo que designa a los solicitantes de asilo y que se usa en el discurso político contemporáneo alemán. Nota del traductor.

27. D. WONG «Fremdheitsfiguren im gesellschaftlichen Diskurs», en Zwischen den Kulturen?, ed. Matthes, Göttingen, 1992, p. 410 y s. 
La experiencia con los «solicitantes de asilo» está planificada y organizada oficialmente. Existe la oficina para extranjeros, la oficina de la seguridad social, la oficina de inscripción de residentes, etc., pero, por encima de todo, están los bloques de edificios asignados a vecindarios separados.

El terreno de los derechos de los extranjeros y de los refugiados prevé una amenaza: «la nueva política del Estado fuerte» (Herbert Prantl).

La expresión "crimen organizado" se usa como un término clave general que lo abre todo — cada tabú, cada derecho fundamental. El sistema de protección legal construido en los últimos cuarenta y cinco años está debilitado. En derecho criminal y, también, en derecho administrativo se promueven «zonas legalmente libres». La política conservadora considera una subordinación restrictiva el control democrático total. Los derechos fundamentales se vuelven abiertamente nulos cuando el fuerte Estado dice que está «mejor» sin ellos $[\ldots]^{28}$.

Esto quiere decir que los modelos de percepción y acción de la sociedad del riesgo se trasladan a los «riesgos de civilización en una democracia liberal» (Ronald Hitzler). Los peligros ecológicos ocupan el lugar de una sospecha general de anomia. Allí se negocian los fundamentos de la producción industrial, de forma que aquí los fundamentos de un estado constitucional liberal se negocian nuevamente.

La política está creando un nuevo estado. En el Estado de seguridad del año 2000 ya no se tratará de perseguir delitos y prevenir peligros concretos, sino de evitar riesgos ya concebibles. En este Estado se considerará y se tratará a cada ciudadano como un factor de riesgo. Un estado que se ve a sí mismo como una organización para evitar riesgos cede cada vez menos libertad a la población. La ansiedad de los ciudadanos por el crimen, como su ansiedad por los refugiados, es una ansiedad que promueve el Estado. El resultado es que cada evaluación del Estado consigue la aprobación general, porque tan sólo promete más seguridad. La gente en este Estado cree que está temporalmente en un club de vacaciones bien vigilado $-\mathrm{y}$ se dan cuenta demasiado tarde de que se trata de una prisión noble. El tipo de "civismo" que la política conservadora ha exigido recientemente implica la renuncia a la individualidad y a los derechos de los individuos ${ }^{29}$.

\section{4. ¿Cómo las imágenes del extraño devienen imágenes del enemigo?}

De los argumentos anteriores, se puede extraer una consecuencia esencial. Cualquiera que, como Karl Otto Hondrich, reduzca el estallido de violencia y las tendencias racionalizadoras de Europa, los antepasados oprimidos a la

28. H. Prantl, «Es wird ungesund in Deutschland», Süddeutsche Zeitung, agosto 13/14, edición de fin de semana, V2/27.

29. Ibídem, comparar también H. A. Hesse, Der Schutzstaat (Baden-Baden, 1994); y también F. EWALD, Der Vorsogestaat, Frankfurt am Main, 1989, p. 361. 
identidad étnica, a la cultura o a la lengua de la gente, comete, al menos, dos categorías de errores ${ }^{30}$. Primero, esencializa la identidad cultural y, segundo, la confunde con el poder calculado de las imágenes del enemigo. Así, se oculta una objeción principal de la lógica de la in-group y la out-group que es característica no sólo de las teorías sociobiológicas y etnológicas de la agresión y el conflicto, sino también de la teoría social, desde Émile Durkheim y Georg Simmel hasta Max Weber y las teorías de grupo del interaccionismo y el existencialismo. Esto no quiere decir nada de la construcción social y la dramaturgia de imágenes especificas del enemigo.

En este sentido, es necesario distinguir — junto con la cuestión sobre cómo las imágenes de los extraños se construyen culturalmente, socialmente, políticamente o burocráticamente- entre los estereotipos de los extraños cotidianos, por un lado, y las imágenes del enemigo, por otro. Las preguntas que esta diferencia justifica son: ¿por qué se dramatizan sólo determinadas identidades culturales y no otras como imágenes nacionales y estatales del enemigo? ¿Y por qué las imágenes del enemigo y del amigo a menudo cambian tan rápidamente? Así, en la América prerrevolucionaria, la «madre patria» Inglaterra (con la misma lengua, la misma etnicidad, las mismas convicciones fundamentales políticamente republicanas) era "el enemigo natural», mientras que más tarde, en el siglo veinte, durante la Segunda Guerra Mundial, el enemigo se volvió «el aliado natural». Aquello que en un espacio social concreto, en una determinada época, se considera "nuestro» y «extraño» no es natural, más bien es una cuestión empírica e histórica difícil de prever y de predecir.

Gottfried Benn hace una observación bajo el encabezamiento «Contenido de la historia»:

Para informarme, abro un viejo libro de escuela: el denominado Pequeño Ploetz $^{31}[\ldots]$ Abro cualquier página, la página 337, sobre el año 1805. Encuentro: una victoria naval, dos alto el fuego, tres alianzas, dos coaliciones. Alguien marcha, alguien crea una alianza, alguien unifica sus tropas, alguien refuerza algo, alguien adelanta, alguien captura, alguien retrocede, alguien captura un campamento, alguien dimite, se concede algo, alguien inaugura algo de manera espectacular, alguien es un prisionero de guerra, alguien compensa a alguien, alguien amenaza a alguien, alguien marcha hacia el Roine, alguien marcha por la zona d'Ansbach, alguien marcha sobre Viena, se hace retroceder a alguien, alguien es ejecutado, alguien es asesinado - al fin y al cabo es, sin duda, la enferma historia de los locos ${ }^{32}$.

Precisamente esta «enferma historia de los locos» refuta la conclusión sobre un potencial de conflicto diagnosticado sociobiológicamente (etnológica o antropológicamente) y que pertenece intrínsecamente a las correspondientes

30. K.O. Hondrich «Grenzen gegen die Gewalt», Diezcit, n. 5, 28 enero, 1994, 4.

31. Der Kleine Ploetz, el léxico alemán estándar. Nota del traductor.

32. G. BENN, Essays und Reden, Frankfurt am Main, 1989, p. 362. 
trifulcas o formaciones de batalla. Los emigrantes alemanes, por ejemplo, que provenían de las restricciones feudales y el recelo de Europa, han vivido en Estados Unidos en buenas relaciones con los negros, han aceptado los matrimonios mixtos, han padecido y han defendido un país originariamente democrático donde la esclavitud en aquellos tiempos se protegía legalmente. La sociobiología o la sociología siguen sin convencer con respecto a los estereotipos sociales del extraño y el yo en relación con la historia social de las imágenes del enemigo. Esto se tiene que ver en el contexto del Estado, el Estado nacional, el ejército, y también en su importancia en la legitimación del monopolio del poder por parte del Estado.

Y aun así, las leyendas han conservado su maldita fuerza hasta el presente, presuponiendo que el yo se tiene que separar y desmarcar enfrente del extraño para poder mantener su identidad. La podríamos denominar la «teoría territorial de la identidad». Esta teoría presupone un espacio reforzado por vallas (mentales) que posibilita la autoconsciencia. Aun así, cuando sacamos esta idea del contexto del que emerge, es decir del Estado nacional, pierde verosimilitud. Los errores en que se han convertido las diferentes historias codificadas y emotivas se los podría denominar errores carcelarios de identificación. No se tiene que aislar, orientar y organizar a las personas porque vayan las unas en contra de las otras - y menos en el vasto espacio de la nación-, para que puedan resultar confiadas y seguras de ellas mismas. ¿Por qué sólo se puede conocer a alguien frente a frente, de manera idéntica y segura, en la celda de una prisión estatal? La franqueza y la mezcla de "prisioneros» ya ofrece mucho material y también la oportunidad para el descubrimiento y la formación de la identidad.

Zygmunt Bauman está atento a este error teórico y ha dejado bien claro que la lógica separadora de la identidad aún permanece en la metafísica unidimensional que inspira la modernidad. ¡Imaginamos la identidad como algo claro, o esto o aquello, excluyendo del todo una tercera posibilidad! Las posibilidades de la identidad ambivalente en una mezcla de multiplicidad y rareza quedan prácticamente fuera de la perspectiva de conseguir y establecer un yo ${ }^{33}$. La teoría de la prisión sobre la identidad ignora la riqueza sobre cómo es de importante para el yo el extraño y su transformación en rareza.

Las «imágenes del enemigo» son aumentadas de manera espectacular y se legitiman. Prejuicios y estereotipos del extraño producidos culturalmente (disponibles) se usan para la construcción y el reforzamiento del poder estatal y del aparato militar. Las imágenes del enemigo — a diferencia de los estereotipos del extraño y los prejuicios raciales - hacen posible una reevaluación de los valores. Aquí alguien puede, tiene que (en caso de guerra) ser eliminado. No hay junta de arbitraje, ni tribunal de justicia para las imágenes del enemigo. Las imágenes del enemigo describen una segunda, próxima, externa —incluso contrademocrática - fuente del moderno Estado (nacional), el cual 
se hace cada vez más atractivo para los actores estatales ante las dificultades de construir un consenso democrático.

La consecuencia es que estamos cultural y científicamente desconectados para poder volver a las tradiciones o a las identidades étnicas, para legitimar la rareza y las diferencias entre el in-group y el out-group. Dicho de otro modo, la etnicidad no es una variable original de la diferenciación social, es totalmente una construcción política y burocrática ${ }^{34}$. No hay ningún tipo de conclusión imaginable por lo que se refiere a la diferencia cultural definida, a las diversas percepciones del extraño y del yo, y a las variedades de dramaturgia política y de construcción de imágenes del extraño y del enemigo. Estas producciones sirven de coartada para la naturaleza, la herencia, las cosas originales y esenciales, pero llevan a término decisiones, selecciones y construcciones que son invenciones.

En la modernidad reflexiva, la construcción del extraño se politiza en un doble sentido. Por un lado, la politización del tema de la seguridad moviliza a los instrumentos de control de la sociedad civil y del Estado fuerte; por otro, la figura del extraño burocráticamente (construido) toma el lugar del extraño cultural. El discurso de la diferencia cultural está cargado del discurso sobre imágenes del enemigo, cosa que legitima la construcción y el reforzamiento de la seguridad preventiva y del Estado protector.

La conversación habitual sobre la lógica del in-group y del out-group de muchas tradiciones teóricas y de investigación de las ciencias sociales (y sociobiologia) esconde este proceso de selección, origen y politización. Una crítica de la discusión teórica del sistema relativa a la exclusión y/o inclusión tendría que empezar por aquí. Con la generalidad de ideas, suprime la incomodidad de procesos de separación específicos dentro el sistema administrativo y político, y los medios de comunicación públicos, etc. El importante papel de los intelectuales en la fundación y preparación de la legitimación de modelos a partir de los que la silueta del extraño se podría fabricar y suministrar a la cadena de montaje se hace invisible. Se puede ver este proceso de selección cuando las relaciones entre el in-group y el out-group se equiparan a la identidad nacional (patriotismo, nacionalismo). ¿Por qué las identidades regionales no se identifican con una autoconsciencia de Europa? ¿Por qué, por ejemplo, el separatismo francófono no se mezcla con el orgullo profesional y con una identidad civilizada para conseguir la autoconsciencia a partir de la garantía de la racionalidad técnica y legal? No estoy diciendo que todo se pueda combinar. Pero quiero manifestar que, con la duplicación, individualización y globalización de los mundos sociales en que nuestra vida está situada, existe un mosaico casi inagotable de exclusiones posibles. Por lo tanto, sería ingenuo (quizás estratégicamente ingenuo) hablar de «inclusión» y «exclusión». En su lugar, surge la cuestión de la unidad de la diferencia y la identidad, de la inclusión y de la exclusión. 
Este es el horizonte que abre, socialmente y políticamente, la pregunta formulada sobre la definición social y política y la construcción de extraños e imágenes de enemigos. Da calculabilidad a la realidad del potencial cultural para la violencia, sin caer, sin embargo, en un fatalismo político. La atención central se dirige a los procesos de construcción públicos, políticos y administrativos diarios - $\mathrm{y}$ a su prevención. Como ya hemos indicado anteriormente: cómo los vecinos se hacen (los convierten en) judíos. En primer lugar, este llegar a ser (werden) no es pasivo, sino activo. En segundo lugar, ciertamente se excluye el pasado «se hicieron» (wurden); es consciente de las amenazas reales y llama la atención. En tercer lugar, sobre una antigua y más feliz defensa y creación de una sociedad abierta y del Estado constitucional liberal. 